\title{
Management Implications of Sexual Differences in Maturation and Spawning Mortality of Northeast Arctic Cod
}

\author{
Tore Jakobsen and Adnan Ajiad \\ Institute of Marine Research, P. O. Box 1870 Nordnes \\ N-5817 Bergen, Norway
}

\begin{abstract}
There is evidence of earlier maturation in males than in females and indications of higher mortality among mature males than mature females in the Northeast Arctic cod (Gadus morhua L.) stock. Both factors affect the composition of the spawning stock by sex and age. One possibility is that spawning mortality is involved. Spawning mortality may occur in both sexes, but observations indicate that it might be higher in males. The possibility of a spawning mortality is investigated by adding spawning mortality in calculations of the history of a year-class to see if this improves the fit with observed sex ratios in commercial landings from the Lofoten spawning fishery. The best fit was obtained for a spawning mortality of about 0.05 on the males. However, the results are not conclusive. Splitting the spawning stock into males and females shows that the earlier maturation in males has a larger impact on the sex ratio in the spawning stock than the spawning mortality rates. Increasing the fishing mortality rates will increase the surplus of male spawners. The results have implications for estimation of biological reference points and the way spawning stock biomass is used in management considerations. Estimation of the female SSB is necessary if maternal effects are to be taken into account.
\end{abstract}

Key words: Arctic, cod, maturation, mortality, Northeast Atlantic, spawning

\section{Introduction}

Estimates of spawning stock biomass (SSB) are important in management advice. The level of SSB can be a decisive factor in quota agreements and the relationship between SSB and recruitment is used to estimate biological reference points for both biomass and fishing mortality.

Ajiad et al. (1999) show that there has been a clear and consistent sexual difference in maturation in Northeast Arctic cod (Gadus morhua L.) across years during the period 1989-97. On average males mature approximately one year earlier than females. This will influence the sex composition in the spawning stock and SSB will be a biased measure of both female and male spawning potential. However, current stock assessment approaches do not take into account sexual differences in maturation.

Recent research indicates that maternal effects on egg survival are important (Kjesbu et al., 1991, Marshall et al., 1998). On the other hand, the results of Trippel and Neilsen (1992) and Trippel and Morgan (1994a, b) indicate that paternal effects play only a modest role in the spawning process. Therefore, if there are sexual differences in maturation, failure to take the female spawning stock into account might have implications for fishery management.

Samples from commercial landings on the spawning grounds of Northeast Arctic cod show that the ratio of male/female spawners declines with age. Males dominate the youngest age groups, whereas females dominate older age groups. The dominance of males in the youngest age groups might be caused by earlier maturation in males or a dominance of male recruits. The results of Ajiad et al. (1999) confirm earlier maturation in males, whereas data from the same surveys indicate that the sex ratio in immature fish is close to $1: 1$. The dominance of females in older age groups might be caused by a higher spawning mortality in males or by a combined effect of earlier maturation in males and higher exploitation rates on mature than on immature fish. 
It is difficult to distinguish spawning mortality from other natural mortality. Beverton et al. (1994) examined individual maturation cohorts of Northeast Arctic cod and their results indicate that spawning mortality might be higher in fish maturing at age 6 or 7 than in fish maturing later. Their estimate of natural mortality rate for these three groups were $0.27,0.17$ and 0.15 , respectively. In the stock assessment a natural mortality rate of 0.2 is normally assumed for the oldest age groups (ICES, MS 1999).

The goal of this study is to evaluate evidence of sexual differences in spawning mortality and to use the results together with the results of Ajiad et al. (1999) to identify possible implications for fishery management.

\section{Materials and Methods}

Most of the data, which are based on Norwegian (Institute of Marine Research) research surveys in the Barents Sea and Lofoten in 1989-97, are taken from Ajiad et al. (1999). The remainder of the data are from commercial landings in the Lofoten region, the main spawning grounds for Northeast Arctic cod. These landings are from gill net, long line, hand line and Danish seine (trawling is prohibited in the area). Both the survey data and the commercial fishery data include sampling of age, length and maturity stage (for more details, see Ajiad et al., 1999). Data from the most recent assessment of Northeast Arctic cod (ICES, MS 1999) are also used.

The mean exploitation (selection) pattern for Northeast Arctic cod in 1989-97 increases up to age 8 and is fairly flat for older ages. The lower exploitation of the younger fish results primarily from gear selectivity and minimum landing size regulations which allow temporary closure of areas with high proportions of undersized fish. When the fish mature they are in addition to the trawl fishery also caught in the spawning fishery. Mature fish are therefore subject to a heavier fishing pressure than immature fish of the same age. However, to establish the difference requires a separation of all catches into mature and immature fish, and these data were not readily available. The exploitation patterns used in this study for immature and mature fish, respectively, are therefore based on a subjective evaluation of the available information. This indicates that the maximum fishing mortality rate of immature fish is approximately 0.2 lower than for mature fish.

The potential role of sexual differences in spawning mortality was evaluated by simulating the progress of a year-class in the stock applying the average natural and fishing mortality rates for 1989-97 (ICES, MS 1999). The simulation was done separately for males and females, using the maturity ogives (means for 1989-97) estimated by Ajiad et al. (1999). The resulting mean ratio 198997 of male/female spawners at each age was then compared to those observed in the commercial landings from the same period. It is assumed that the catches on the spawning grounds reflect the age and sex composition of the mature stock. The minimum sum of least squares was used as indicator of which addition to the natural mortality on mature males gave the best fit between the resulting ratios of male/female spawners and the values observed in the commercial fishery data for the age groups 5-13 (data on older fish were few and noisy). The results were used to estimate yield, SSB and numbers of spawners per recruit (at age 3 ) for the sexes separately.

In spite of the difference in maturation, there is little difference in growth between the sexes (Ajiad et al., 1999). In immature fish the females tend to be slightly larger (approximately $0.5 \mathrm{~cm}$ ) than the males in the same age group. In mature fish the difference tends to increase with age, but is still small. In this study growth, or more precisely weight at age, is assumed to be the same for both sexes.

Table 1 shows the Excel worksheets used in the calculations (results of - per recruit calculations excluded).

The following comments referring to the number of the column apply both to males and females:

1) Stock number-at-age, starting with one recruit at age 3 (sum of col. 4 and 5).

2,3) Numbers of immature and mature fish at age. The split is based on col. 1 and 23 .

4,5) Numbers of immature and mature fish at age $i$ surviving to age $i+1$.

$6,7,8,9)$ Catch in numbers; yield, stock biomass and spawning stock biomass in $\mathrm{kg} \mathrm{10,11)}$ Exploitation patterns for immature and 


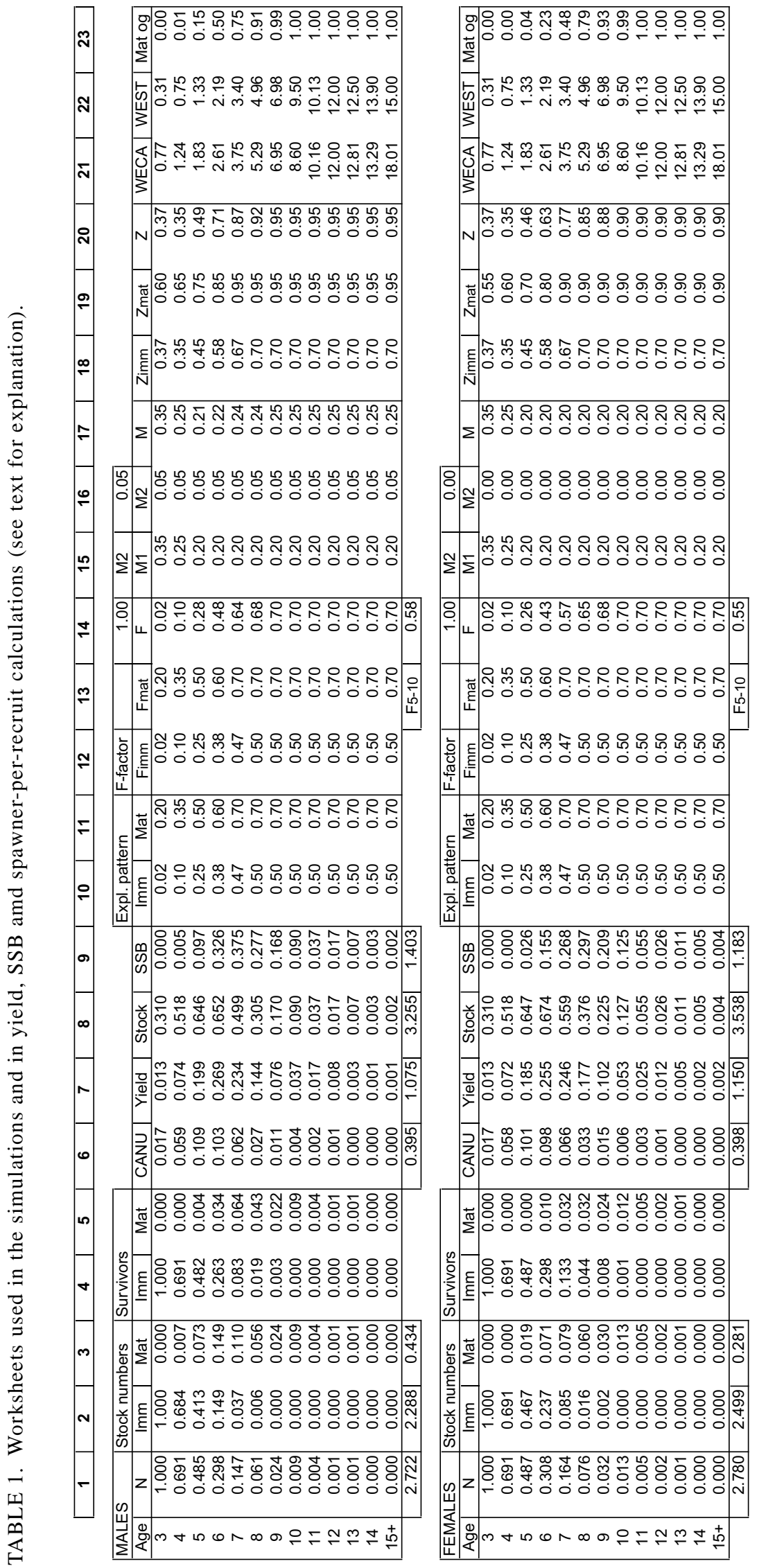


12,13) Fishing mortalities for immature and mature fish (col. 10 and 11 multiplied by F-factor).

14) Total fishing mortality, derived from col. 1,6 and 20. These values correspond to smoothed values for 1989-97 from the most recent assessment.

15) Natural mortality, smoothed values for 1989-97 from the most recent assessment.

15) Spawning mortality, or more precisely added natural mortality on mature males.

Values varied to give the best fit to the observations.

17) Total natural mortality (derived from col. 14 and 20).

18) Total mortality on immature fish (sum of col. 12 and 15).

19) Total mortality on mature fish (sum of col. 13, 15 and 16).

20) Total mortality, derived from col.1.

21,22) Mean weight at age in catch and stock, smoothed averages for 1989-97.

23) Maturity ogives for males and females, averages for 1989-97.

\section{Results}

Spawning mortality might occur in many different ways. Some possible scenarios are:

1. Spawning mortality is constant, and the same for both sexes.

2. Spawning mortality is constant, but different for the sexes.

3. Spawning mortality increases with each spawning, in the same way for both sexes.

4. Spawning mortality increases with each spawning, but in a different way for the sexes.

5. Spawning mortality decreases with each spawning, in the same way for both sexes.

6. Spawning mortality decreases with each spawning, but in a different way for the sexes.

The two last scenarios would be consistent with the results of Beverton et al. (1994).

All these scenarios were tested, although for simplicity increase or decrease in spawning mortality rate was assumed to be linked to age rather than to the spawning class. Within reasonable ranges of total mortality rates the results were fairly consistent, showing a difference in spawning mortality in the range $0.01-0.10$, mostly close to 0.05 , with males always having the higher value. Change in natural mortality with age or in the estimated exploitation on the immature fish made little difference. Considering only the oldest age groups (10-13) gave a larger difference in spawning mortality rate, approximately 0.13 . However, assuming a change in spawning mortality with age over the whole age range gave a poorer fit than assuming spawning mortality constant with age.

The table below shows the ratios male/female spawners observed in the commercial data and the corresponding results of a simulation with no female spawning mortality, and male spawning mortality assumed to be constant with age. In the calculation of yield, SSB and numbers of spawners per recruit, the spawning mortality for females is assumed to be zero and for males it is assumed to be 0.05 .

\begin{tabular}{rcc}
\hline Age & $\begin{array}{c}\text { Observed } \\
\text { male/female ratios }\end{array}$ & $\begin{array}{c}\text { Simulated } \\
\text { male/female rations }\end{array}$ \\
\hline 5 & 3.82 & 3.74 \\
6 & 1.98 & 2.10 \\
7 & 1.28 & 1.40 \\
8 & 1.09 & 0.93 \\
9 & 0.91 & 0.80 \\
10 & 0.90 & 0.72 \\
11 & 0.72 & 0.67 \\
12 & 0.66 & 0.64 \\
13 & 0.54 & 0.61 \\
\hline
\end{tabular}

Figure 1 shows the results of the yield per recruit calculations. $F_{\max }$ for females is at 0.25 , for males at 0.34 and for both sexes combined at 0.29. Yield per recruit is higher for females than for males but the difference decreases as the fishing mortality rate increases. At recent levels of fishing mortality $(0.4-0.8)$ observed in the stock the difference is 4$9 \%$. The differences between the curves are almost exclusively caused by the assumed spawning mortality.

Figure 2 shows SSB per recruit for each sex and Fig. 3 shows the ratio male/female SSB. In a virgin stock the female SSB will be nearly $30 \%$ larger than the male SSB, but there is a substantial effect of the fishing mortality and the SSB levels will be equal already at $F=0.2$. At recent levels of 


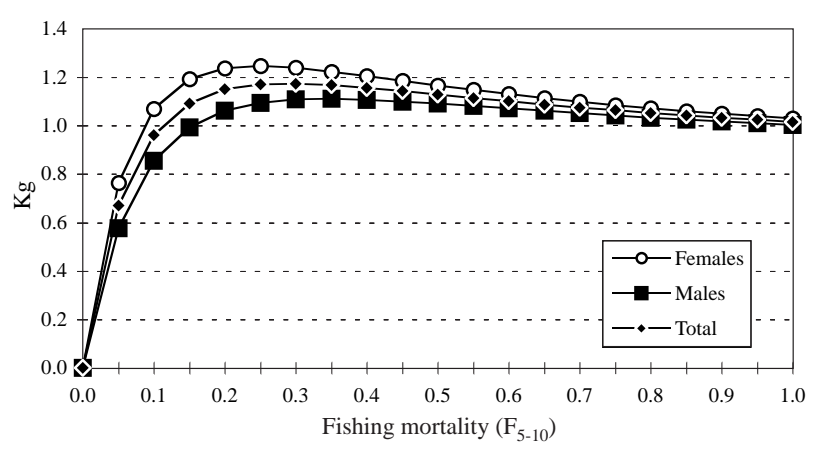

Fig. 1. Yield-per-recruit calculations for different fishing mortality rates.

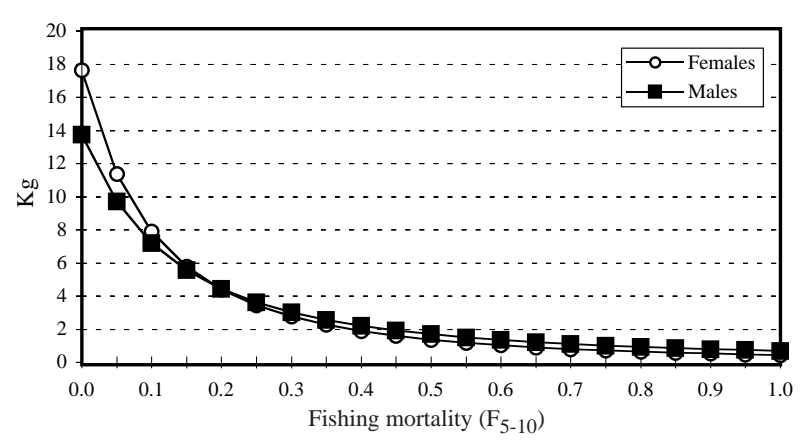

Fig. 2. Spawning stock biomass per recruit for different fishing mortality rates.

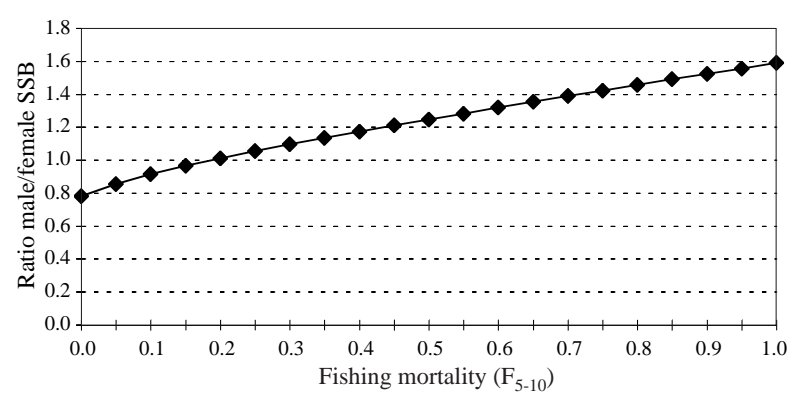

Fig. 3. The ratios male/female spawning stock biomass at different fishing mortality rates.

fishing mortality the male SSB is $20-45 \%$ larger than the female SSB. This also means that the female SSB is more rapidly reduced from the pristine stock level as fishing mortality increases (Fig. 4).

The difference is more pronounced in the number of spawners (Fig. 5 and 6). In a virgin stock the numbers of male and female spawners will be approximately the same, but at an F of 0.42 there will be $50 \%$ more males than females in the spawning stock and twice as many if $\mathrm{F}$ exceeds 1.0.
In Fig. $2-5$ the effect of assuming no spawning mortality would be an increase of the males which will be most pronounced near the pristine level. At recent levels of fishing mortality the male/female ratio will also increase, but only slightly. The slopes of the lines representing the change in male/female ratio with increasing fishing mortality (Fig. 3 and 6) will only be marginally changed and are mainly caused by the earlier maturation in males.

\section{Discussion}

The present simulations show that the best fit with the observed sex ratios is obtained by assuming a higher natural mortality in mature males than in mature females. The results of Beverton et al. (1994) indicate that spawning mortality might be the main component of natural mortality among the mature cod. It is therefore likely that both males and females suffer spawning mortality, but the simulations do not give any indication of absolute levels.

The evidence of a higher spawning mortality in males than in females is not conclusive and the authors, consulting with statisticians at IMR, could not find any meaningful statistical test to apply to the results. In the period studied there were large variations in fishing mortality rate, recruitment and, to a lesser degree, maturation which might affect the results which are based on average values. Additional exploitation on males caused by the earlier recruitment to the spawning fishery is built into the model, but there could be other effects from the commercial fishery. There are, e.g. systematic differences between gears in the sex ratio, up to approximately 60:40 in some cases, but these go both ways and the impression is that catch rates of mature males and females on the whole are not very different.

Even a small sexual difference in spawning mortality has an effect on the estimation of $F_{\max }$ which in general is very sensitive to changes in natural mortality. If the additional spawning mortality on males is included in the calculations, $F_{\max }$ will increase from 0.25 to 0.29 . It could also have some effect on the calculation of other reference points and should not be ignored as a potential source of bias.

However, for Northeast Arctic cod the sex difference in maturation is probably more important. If female SSB is considered a better measure of 


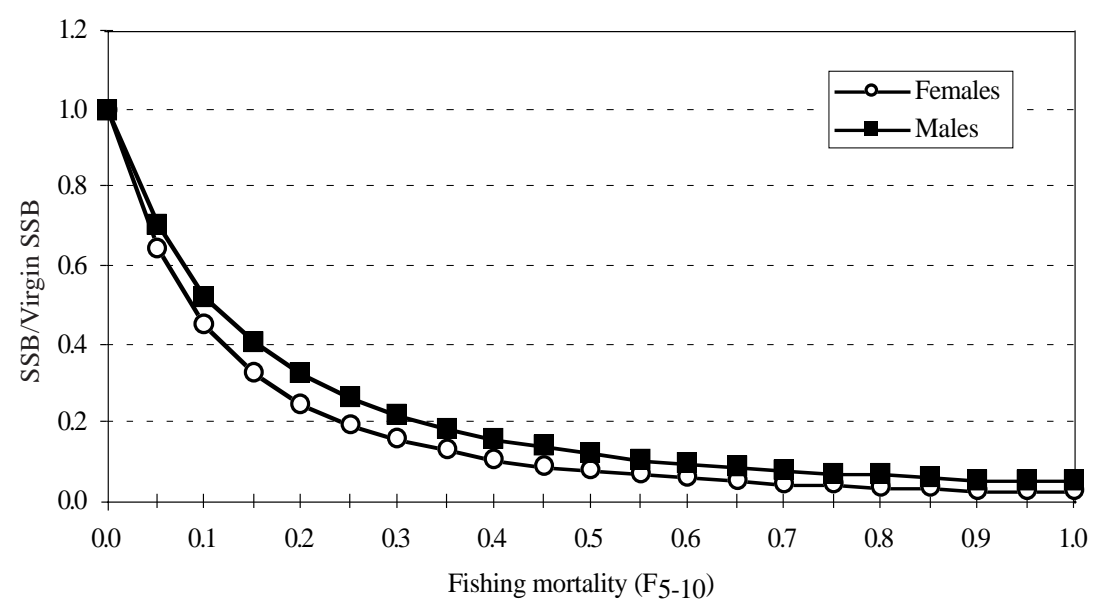

Fig. 4. Spawning stock biomass relative to virgin stock at different fishing mortality rates.

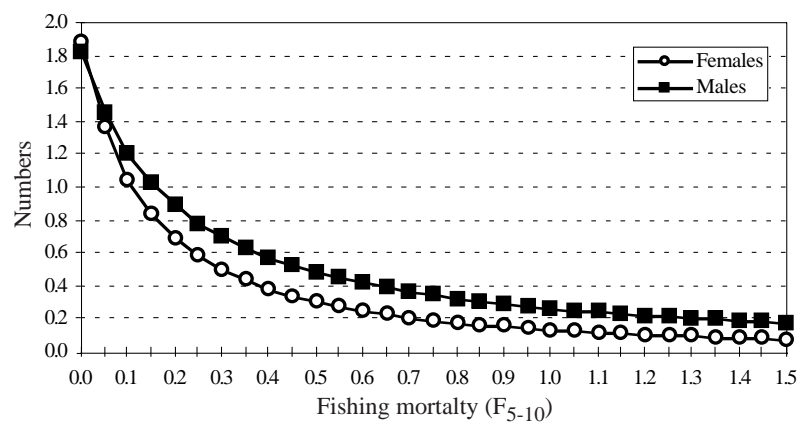

Fig. 5. Spawners per recruit at different fishing mortality rates.

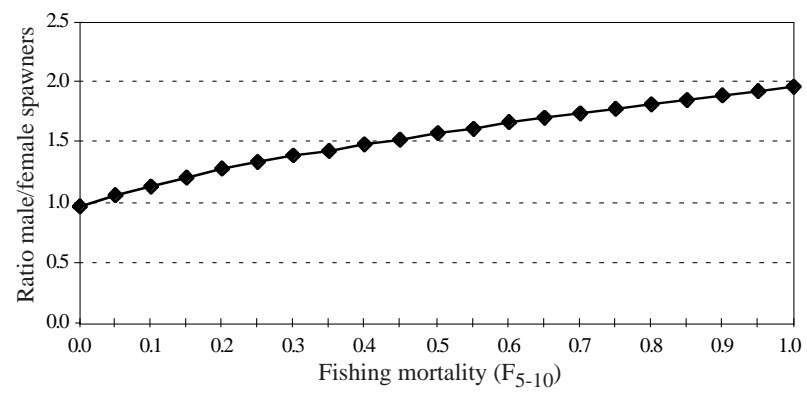

Fig. 6. Ratio of male to female spawners at different fishing mortality rates.

recruitment potential than the total SSB, assuming that the latter is proportional to female SSB will give biased results. Therefore, if maternal effects are to be taken fully into account, a measure of female SSB and its age and size composition are needed.
One striking result of the study is how the ratio of male/female spawners varies with the fishing mortality. The calculations show that in a virgin stock the numbers of male and female spawners are approximately equal and this indicates that at the pristine stock level a surplus of males is not needed to ensure that enough eggs are fertilized to give satisfactory recruitment. If the ratio predicted at lower fishing mortalities is sufficient to ensure fertilization of all the eggs, an increase in the fishing mortality will tend to generate a surplus of unproductive males in the spawning stock. These males will compete with the other mature cod for food which could have a negative effect on egg production and quality. However, it is also possible that there is always a substantial number of eggs that are not fertilized. Increasing the male/female ratio might then ensure that a higher proportion of the eggs is fertilized and thereby counteract the negative effects of a reduction in the female spawning stock. A more detailed study and a longer time series of data are needed to investigate the effects the male/female ratio might have on the recruitment and whether density dependent factors can influence the ratio.

It is quite possible that taking sexual differences in maturation into account and using the female spawning stock as the basis could have important consequences for management advice. Unfortunately, historical SSB estimates for Northeast Arctic cod are not easily split by sex and a considerable effort and probably international 
cooperation is needed to establish a reliable time series of female SSB. This will be an aim for future work. In the meantime, it would be interesting to see if other cod stocks show the same properties, and to conduct further studies which might demonstrate the desirability of using female spawning stock as the basis for management advice.

\section{Acknowledgement}

The authors thank the editors for patience in waiting for the final version of the article, which has given us the opportunity to remove errors and improve on the presentation. We also thank the two referees for pointing out shortcomings in the first draft and for helpful suggestions for improvement.

\section{References}

AJIAD, A., T. JAKOBSEN, and O. NAKKEN. 1999. Sexual difference in maturation of Northeast Arctic Cod. J. Northw. Atl. Fish. Sci., 25: 1-15 (this volume).

BEVERTON, R. J. H., A. HYLEN, and O. J. OSTVEDT.
1994. Growth, maturation, and longevity of maturation cohorts of Northeast Arctic cod. ICES Mar. Sci. Sym., 198: 482-501.

ICES. MS 1999. Report of the Arctic Fisheries Working Group. ICES C.M. Doc., No. Assess 2: 1-275.

KJESBU, O., J. KLUNGSØYR, H. KRYVI, P. WITTHAMES, and M. GREER WALKER. 1991. Fecundity, atresia, and egg size of captive Atlantic cod (Gadus morhua) in relation to proximate body composition. Can. J. Aquat. Sci., 48: 2333-2343.

MARSHALL, T., O. KJESBU, N. YARAGINA, P. SOLEMDAL, and Ø. ULLTANG. 1998. Is spawner biomass a sensitive measure of the reproduction and recruitment potential in Northeast Arctic cod. Can. J. Fish. Aquat. Sci., 55: 1766-1783.

TRIPPEL, E.,A., and J. D. NEILSEN. 1992. Fertility and sperm quality of virgin and repeat-spawning Atlantic cod (Gadus morhua) and associated hatching success. Can. J. Fish. Aquat. Sci., 49: 2118-2127.

TRIPPEL, E. A., and M. J. MORGAN. 1994a. Agespecific paternal influences on reproductive success in Atlantic cod (Gadus morhua) of the Grand Banks, Newfoundland. ICES Mar. Sci. Symp., 198: 414-422.

1994b. Sperm longevity in Atlantic cod (Gadus morhua). Copeia 1994: 1025-1029. 